\title{
INFLUENCE OF CHEMICAL TREATMENTS ON THE MECHANICAL CHARACTERISTICS OF ARECA SHEATH- FLAX FIBRES BASED EPOXY COMPOSITES
}

\author{
S. Jothibasu', S. Mohanamurugan ${ }^{2, *}$ and A.Vinod ${ }^{3}$ \\ ${ }^{1}$ Department of Mechanical Engineering, St. Peter's Institute of Higher Education and Research, \\ Chennai, Tamil Nadu, India \\ ${ }^{2}$ Department of Mechanical Engineering, Aarupadai Veedu Institute of Technology, Chennai, \\ Tamil Nadu, India \\ ${ }^{3}$ Department of Mechanical Engineering, Sri Lakshmi Ammal Engineering College, Chennai, \\ Tamil Nadu, India \\ * E-mail: drsmm14@gmail.com
}

\begin{abstract}
In the present work, Areca Sheath and Flax fibres were selected as reinforcements. The selected fibres were treated with chemicals namely Hydrochloric acid, Sodium Hydroxide, and Benzyl Chloride. Four different composites were developed using the hand lay-up process, three composites based on treated fibres and one composite with untreated fibres for comparison. Fourier-transform infrared spectroscopy analysis was done to study the functional groups present in the fibres. The developed composites were characterized for its mechanical characteristics namely tensile, flexural, impact and hardness as per ASTM. The tested composites were analysed for its morphological characteristics using Scanning Electron Microscopy. From the results, it was found that sodium hydroxide treatment to fibres was beneficial to improve its mechanical property when compared to the other composites.

Keywords: Areca sheath fibre; Flax fibre; Hand Lay-up process; Fourier-transform infrared spectroscopy (FTIR)

(c) RASĀYAN. All rights reserved
\end{abstract}

\section{INTRODUCTION}

The increase in natural materials have decreased the problems like recyclability, and it has increased the environmental safety ${ }^{1}$. In the present scenario, several synthetic fibres like glass, carbon fibres and aramid fibres are used as a reinforcement in polymer-based composites. They were widely used for an increase in several properties like strength and stiffness. Though these kinds of synthetic fibres have certain advantages, the problems like biodegradability, processing costs, recycling and health issues were not addressed $^{2}$. To overcome these issues several researchers and industries started to reinforce natural fibres in the polymer matrix. Natural fibres can be defined as the fibres, which are not synthetic or humanmade. They are extracted from plants or animals. These natural fibres have reduced the problems associated with the synthetic fibres. The reinforcement of natural fibres in a polymer matrix has increased several mechanical and morphological properties. The increase in physical and chemical properties mainly can be influenced by location in which they grow and how these fibres are extracted ${ }^{3,4}$. Generally, polymers are classified into thermoset and thermoplastics. The natural fibres like hemp, sisal, jute and many fibres have been used mostly used as a reinforcement in the thermoplastic matrix. The benefits of using natural fibres are lightweight, ease of processing, high modulus and absorption of $\mathrm{CO}_{2}$ during their growth. In the present scenario, hybrid composites are developed due to the versatile applications. Madhukiran et al investigated the mechanical behaviour of sisal-coir fiber randomly oriented hybrid epoxy composites. It was proved that hybrid composites possessing (20 wt $\%$ each) equal weight percentage of sisal and coir based composites showed superior results compared to pure fibre composites. Venkateshwaran et al. ${ }^{6}$ developed hybrid composites using banana/sisal fibers with varying fractions in which the overall fiber volume fraction was

Rasayan J. Chem., 11(3), 1255-1262(2018)

http://dx.doi.org/10.31788/RJC.2018.1133096

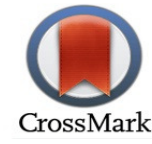


fixed as $0.4 \mathrm{Vf}$. Results showed that composites with $0.2 \mathrm{Vf}$ each fibre possess good tensile properties. These natural fibres are made of cellulose, hemicellulose, lignin, pectin and waxy substances. The absorption of moisture during the processing of natural fibres makes the bonding so poor with the matrix materials ${ }^{7}$. The chemical structures of the matrix and the natural fibres are different, and the coupling of these becomes challenging. This causes an ineffective stress transfer between the matrix and the fibres. To overcome these problems, certain chemical treatments must be carried out for the natural fibres. These treatments are carried out based on the functional groups, which reacts with the natural fibres, and it changes its composition. As the result of the chemical treatment, the moisture absorption of fibres is reduced and thus increases the bonding between the matrix and the natural fibres. The natural fibres which are reinforced in the polymer matrix are in the form of short-randomly oriented, unidirectional and woven fabrics ${ }^{8}$. The different type of treating of natural fibres was investigated by several researchers. The different type treatment of natural fibres which are usually done is silane, alkali, acrylation, benzoylation, maleated coupling agents, triazine, fatty acids and many more treatments ${ }^{9}$. Benyahia et al. ${ }^{10}$ treated alfa fibres with $1,3,5$ and $7 \%$ sodium hydroxide solution for one day. The tensile and flexural properties of their composites were increased when the fibres were treated with after alkali treatment, and it was best at 7\%. Compared to the untreated fibres composites, there was an increase in tensile and flexural strengths of $7 \%$ treated composite by $30 \%$ and $50 \%$; which were due to high better interfacial adhesion of the alfa with the polyester resin. Jacob et al. ${ }^{11}$ studied the chemical treatment of sisal-oil palm hybrid composites and reported their properties. During the benzoylation, treatment benzoyl chloride is used for decreasing the hydrophilic nature of the natural fibres, and it increases the interfacial adhesion which also increases the strength of the resulting composite. The alkali treatment is usually carried out. During this process, the lignin, waxes and oil covering materials are removed from the natural fibre surface, and there is an exposure of $\mathrm{OH}$ group in the surface. After this process, the natural fibres are treated with benzoyl chloride. The $\mathrm{OH}$ group fibre are replaced by benzoyl group and it is attached on the cellulose backbone ${ }^{12}$. Joseph et al. ${ }^{13}$ carried out benzoyl chloride treatment of sisal fibre and found that the thermal treatment of treated fibres were improved when compared to the untreated fibres. From the extensive literature, it was found that there were no works concerning the treatment of dual Areca Sheath Fibre and Flax fibres. The fibres were treated by $\mathrm{HCl}, \mathrm{NaOH}$ and Benzoyl treatment and it was compared with untreated one for checking the improvement in properties. Tensile, flexural, impact and hardness tests were carried out to study the properties of the composites and SEM for studying the surface morphology.

\section{Materials and Development Process}

\section{EXPERIMENTAL}

Areca Sheath and Flax fibres were collected from local distributors. The fibre extraction was done by manual retting process. Areca Sheath and Flax fibres were treated by (1) untreated, (2) treated with $5 \%$ sodium hydroxide $(\mathrm{NaOH}),(3)$ treated with $5 \%$ Benzyl Chloride (4) treated with 5\% hydrochloric acid $(\mathrm{HCl})$ and designated as A1, A2, A3, A4 respectively. Areca Sheath and Flax fibres composites were prepared by hand layup process. During the composite preparation $40 \%$ of Areca Sheath Fibre and Flax fibres were mixed with the epoxy-hardener (10:1), i.e. $20 \%$ each fibre. In the current work epoxy matrix of LY556 grade (Bisphenol A Diglycidyl Ether) and hardener of HY951 (triethylenetetramine) were used. In the hand lay-up process, the die of size $30 \mathrm{~cm}^{2}$ was chosen, and the polyvinyl alcohol (PVA) was applied as releasing agent, a coat of PVA was applied to the die and left untouched for drying. Upon drying of the releasing agent, the coat of resin-hardener was done followed by the placing of mixed fibres in the die and matrix mixture was applied to the required volume. Then a load of $25 \mathrm{~kg}$ was placed over the laminate and left untouched for 24 hours for curing in room temperature conditions ${ }^{14}$.

\section{Testing of Composites}

Fourier-transform infrared spectroscopy (FTIR) was carried out for the raw mixed fibres to study the functional groups of the fibres in PerkinElmer/Spectrum 2 Diamond that possess a range of $400-4000$ wave number. The test specimens were cut to desired shape and size as per standard using the cutter. The tensile properties were analyzed as per ASTM D638 in the universal testing machine. The crosshead speed was maintained at $2 \mathrm{~mm} / \mathrm{min}$. Flexural strength of the composites was carried out according to ASTM D790. The loading rate of the test was $2 \mathrm{~mm} / \mathrm{min}$ in the universal testing machine. The energy absorbed due to the 


\section{RASĀYAN J. Chem.}

Vol. 11 | No. 3 |1255 - 1262 | July - September | 2018

impact of the composites were carried out as per ASTM D256-10 in Charpy tester. Scanning Electron Microscopy (SEM) was used to study the fracture behavior of the tested composites using TESCAN Machine of the Czech Republic.

\section{RESULTS AND DISCUSSION}

\section{Fourier-Transform Infrared Spectroscopy (FTIR) Analysis of the Fibres}

The Fourier transform infrared spectrograms of the various chemically treated fibres are shown in figure 1. Table 1 denotes the functional groups present in the in the fibre with respect to the particular wave number. From the wave numbers, we can determine the functional groups present in the fibre and the fibre component which corresponds to the particular functional group.

Table-1: Functional Groups Concerning the Wave Number of The Fibres

\begin{tabular}{c|c|c|c|c|c}
\hline \multicolumn{7}{c|}{ Wave Number cm } & & \\
\hline $\begin{array}{c}\text { Untreated } \\
\text { Fiber }\end{array}$ & $\begin{array}{c}5 \% \mathrm{NaOH} \\
\text { Treated }\end{array}$ & $\begin{array}{c}\mathrm{HCl} \\
\text { Treated }\end{array}$ & $\begin{array}{c}\text { Benzoyl Chloride } \\
\text { Treated }\end{array}$ & Functional Group & Reference \\
\hline 3332 & 3335 & 3326 & 3453 & O-H Stretching & 15 \\
\hline 2913 & 2889 & - & - & CH Symmetrical & 16 \\
\hline 1620 & 1623 & - & 1647 & C=C Bending & 16 \\
\hline- & - & - & 1425 & C-O Stretching & 17 \\
\hline 1028 & 1032 & 1021 & - & C-O stretching Vibration & 16 \\
\hline- & - & - & 845 & C-O Bending & 17 \\
\hline
\end{tabular}

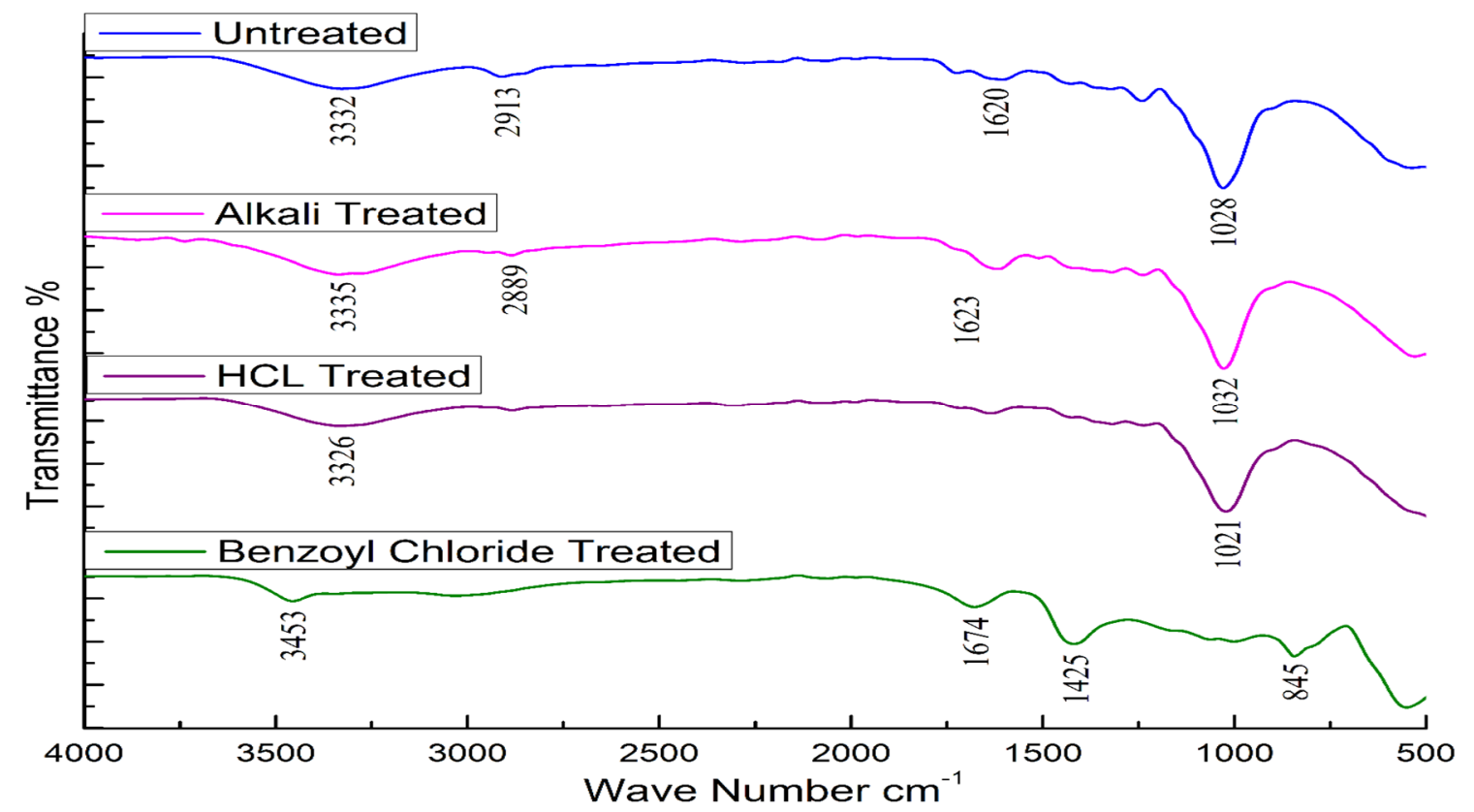

Fig.-1: Fourier Transform Infrared Spectrums of Treated and Untreated Specimens

From the Fig.-1, the first $U$ shaped bend is seen around $3332 \mathrm{~cm}^{-1}, 3335 \mathrm{~cm}^{-1}, 3326 \mathrm{~cm}^{-1}$ and $3453 \mathrm{~cm}^{-1}$ for the untreated and the other three treated samples respectively, which is due to the hydrogen bonded $\mathrm{O}-\mathrm{H}$ stretching, thus determining the presence of $\alpha$-Cellulose ${ }^{15}$. The next small bump is observed at $2913 \mathrm{~cm}^{-1}$, and $2889 \mathrm{~cm}^{-1}$ for untreated and $5 \% \mathrm{NaOH}$ treated samples respectively. This determines the presence of cellulose and hemicellulose due to the stretching of $\mathrm{C}-\mathrm{H}$ and vibration from $\mathrm{CH}$ and $\mathrm{CH}_{2}{ }^{14}$. The next $\mathrm{U}$ shaped bump is observed at $1620 \mathrm{~cm}^{-1}, 1623 \mathrm{~cm}^{-1}$ and $1647 \mathrm{~cm}^{-1}$ for the untreated, $5 \% \mathrm{NaOH}$ treated and Benzoyl Chloride treated samples respectively, which was due to the bending of $\mathrm{C}=\mathrm{C}$, thus attributes the presence of lignin ${ }^{16}$. The next peak is observed at $1425 \mathrm{~cm}^{-1}$ for the Benzoyl Chloride treated samples, which attributes the presence of the aromatic ring in polysaccharides due to the stretching of $\mathrm{C}-\mathrm{O}{ }^{17}$. The next consecutive peaks are observed at $1028 \mathrm{~cm}^{-1}, 1032 \mathrm{~cm}^{-1}$ and $1021 \mathrm{~cm}^{-1}$ for the untreated, $5 \%$ alkali- 
treated and HCL treated samples respectively, which was due to the stretching and vibrations of C-O attributes the presence of acetyl group in lignin ${ }^{16}$. The last bump is seen at $845 \mathrm{~cm}^{-1}$ for the benzoyl Chloride treated sample, corresponds to the stretching of $\mathrm{C}-\mathrm{O}$ attributes the presence of $\beta$-Glucosidic acid ${ }^{18}$.

\section{Tensile Behaviour of the Composites}

The ultimate tensile strength results of the composites are shown in Fig.-2. The treated fibres based composites showed a remarkable improvement of properties except $\mathrm{HCl}$ treated one. This is due to the strong bonding with the matrix. The $\mathrm{NaOH}$ treated fibres based composites shows superior strength when compared to the other composites due to the strong interaction between the fibres and the matrix which is due to the presence of mechanical bonding. The mechanical bonding is due to the increases in the value of surface roughness of the fibres which is facilitated by the improvement in surface roughness of the fibres through hydrogen disruption bonding. The ionization of the hydroxyl group is due to the addition of $\mathrm{NaOH}$ to the natural fibres. The incompatibility of the natural fibres can be done by surface treatments using $\mathrm{NaOH}, \mathrm{CH}_{3} \mathrm{COOH}$, peroxide treatment, etc. The presence of $(\mathrm{OH})$ group in $\mathrm{NaOH}$ donates the electron during the chemical treatment. The electron modifies the fibres through the exposure of the cellulose which increases the chemical bonding and wettability nature of the fibre. The damage of the fibres, when treated with the $\mathrm{NaOH}$ is less. Thus the fibre treatment by $\mathrm{NaOH}$ improved the properties when compared to the other treatment. The same kind of improvement in the fibres was also reported by Vilay et al. ${ }^{19}$ when baggese fibres were chemically treated.

In the case of $\mathrm{HCl}$ treated based composites there was a reduction in properties which could be due to the damage due to the absorption of electrons because of the acidic nature of $\mathrm{HCl}$. The damage of the fibre is also due to the erosion effects caused by chloride ${ }^{20}$. The presence of several porosities and reduction in cellulose contents as inferred from FTIR are found when the fibre was treated with the HCl. The presence of porosities leads to the decrease in the properties of the treated fibres based composites. Thus, when the composites possessing fibres treated with $\mathrm{HCl}$ resulted in inferior properties when compared to all the treated and untreated fibre composites. When the Benzoylation treatment of the fibres was carried out, it leads to enhancement of bonding surface characteristics of the fibre, not to the level of $\mathrm{NaOH}$. But to an extent thus it showed intermediate results. Thus, from the above surface treatment of the fibres, $\mathrm{NaOH}$ treated fibres based composites revealed enhanced ultimate tensile strength when compared to other composites.

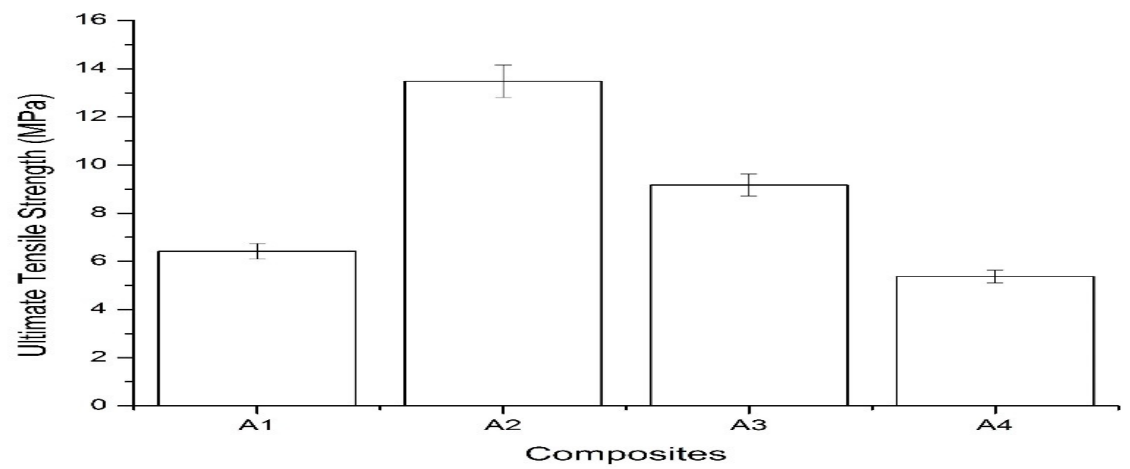

Fig.-2: Ultimate Tensile Strength of the Developed Composites

The stress-strain graph of $\mathrm{NaOH}$ fibres treated composites (A2) are shown in Fig.-3. It can be inferred that the $\mathrm{NaOH}$ sample has great load-bearing capacity due to the proper adhesion of matrix with fibre. The tensile strength was reported to be maximum in this case. The stress-strain curve of the $\mathrm{HCl}$ treated fibre based composites are shown in Fig.-3. It resulted in poor tensile strength when compared to the remaining composites due to the poor load-bearing characteristics caused due to the erosion of the fibres by acid treatment.

\section{Flexural Behaviour of the Composites}

The ultimate flexural strength of the developed composites is shown in Figure 4. While carrying out in the bending test, the top part of the specimen experiences a tensile force while the bottom part experiences a bending force. 
RASĀYAN J. Chem.

Vol. 11 | No. 3 |1255 - 1262 | July - September | 2018

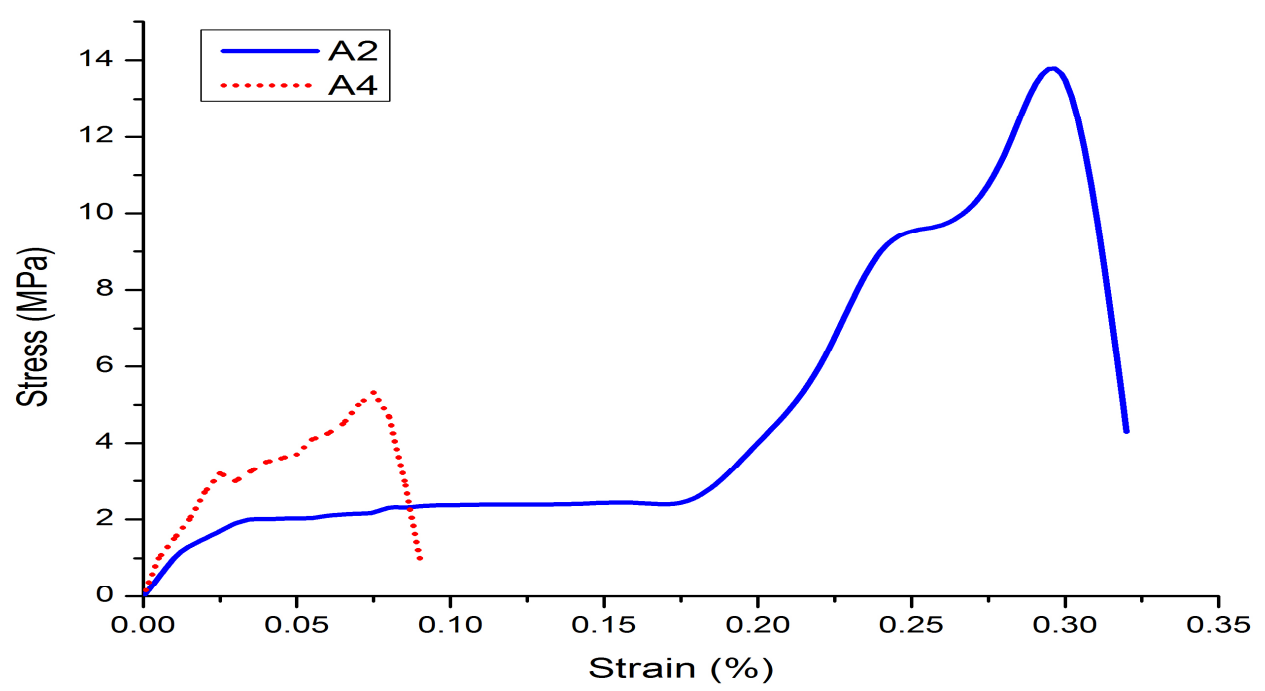

Fig.-3: Stress-Strain Curve for Tensile Tested $\mathrm{NaOH}$ Treated Composites (A2) and $\mathrm{HCl}$ Treated (A4) Composites

In the current work, the $\mathrm{NaOH}$ treated fibres based composites resulted in enhanced bending strength when compared to the other composites. Mwaikambo ${ }^{21}$ also concluded that the flexural strength of the sugarcane fibre reinforced composites was superior when it was treated with $\mathrm{NaOH}$. The $\mathrm{HCl}$ treated fibres based composites resulted in a decrease in properties due to the presence of extensive damage to the fibres. In summary, the $\mathrm{NaOH}$ treated based composites shows better ultimate flexural strength. The stress-strain graphs of superior and inferior results are shown, i.e. A2 and A4 composites are shown in figure 5 respectively. It is inferred that A2 composites showed good elongation compared to A4 composites which helped in maintaining the values.

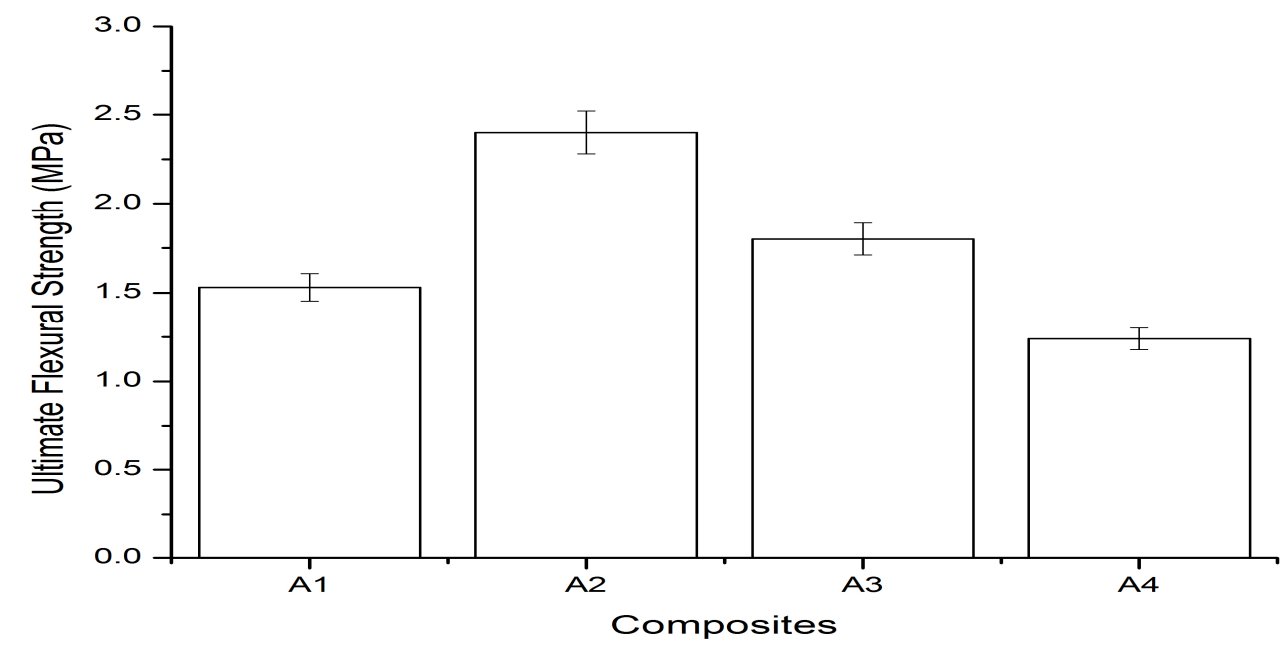

Fig.-4: Ultimate Flexural Strength of Treated and Untreated Composites in Stated Proportions

\section{Impact behavior of the composites}

The impact properties of the treated and non-treated fibres based composites are shown in Figure 6 based on the energy absorbed during impact. Thus revealing, that the impact property was more for composites when the fibre was treated with $\mathrm{NaOH}$ due to the strong bonding between the matrix and fibre. The $\mathrm{NaOH}$ treated fibre based composites becomes stiffer and tough which makes the impact properties to be superior. The impact property of the untreated composites and Benzoylation treated fibres based composites were less when compared to the $\mathrm{NaOH}$ treated fibres based composites. The impact property was worst in the case of $\mathrm{HCl}$ treated based composites due to the excess removal of cellulose and causing the more damage to the fibres. 


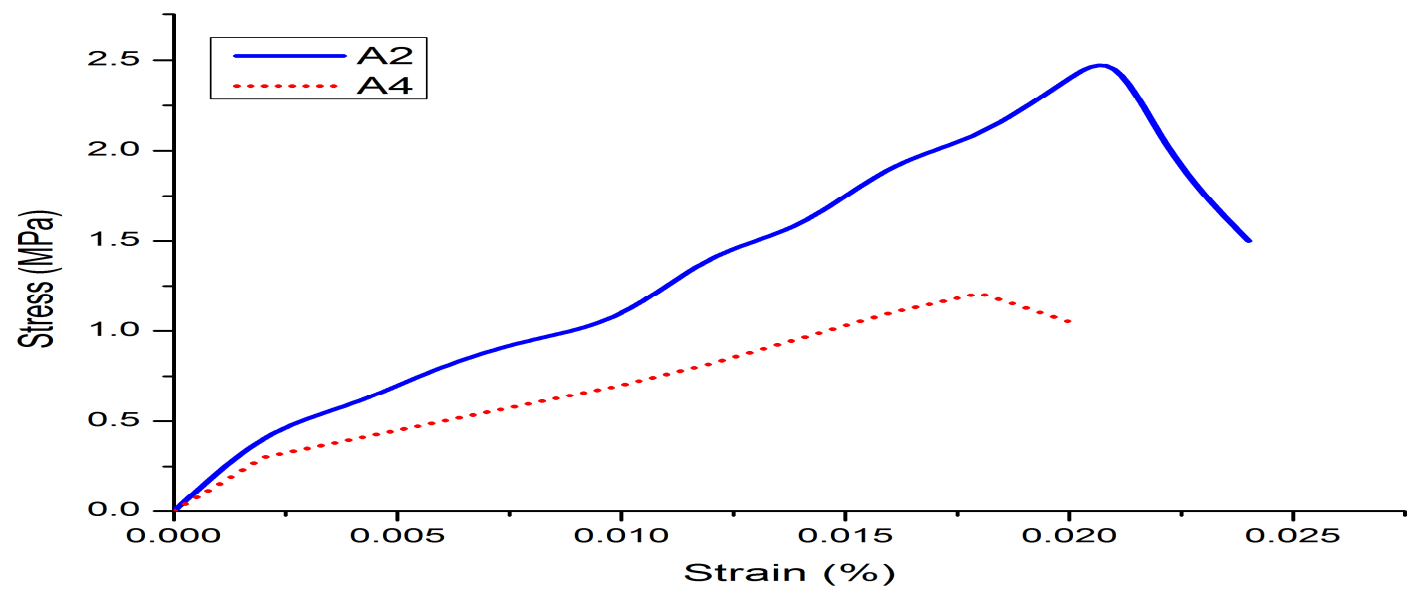

Fig.-5: Stress-Strain Curves of Flexural Tested A2 and A4 Composites

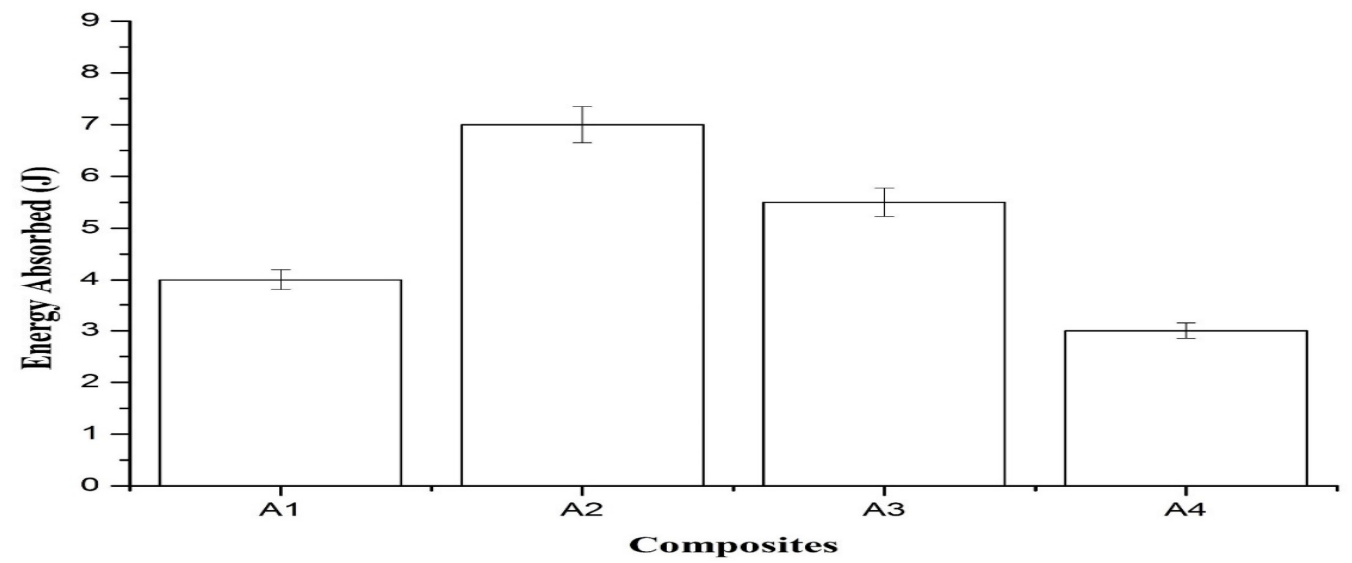

Fig.-6: Energy Absorbed by the Fabricated Specimens

\section{Shore D Hardness Behaviour of the Composites}

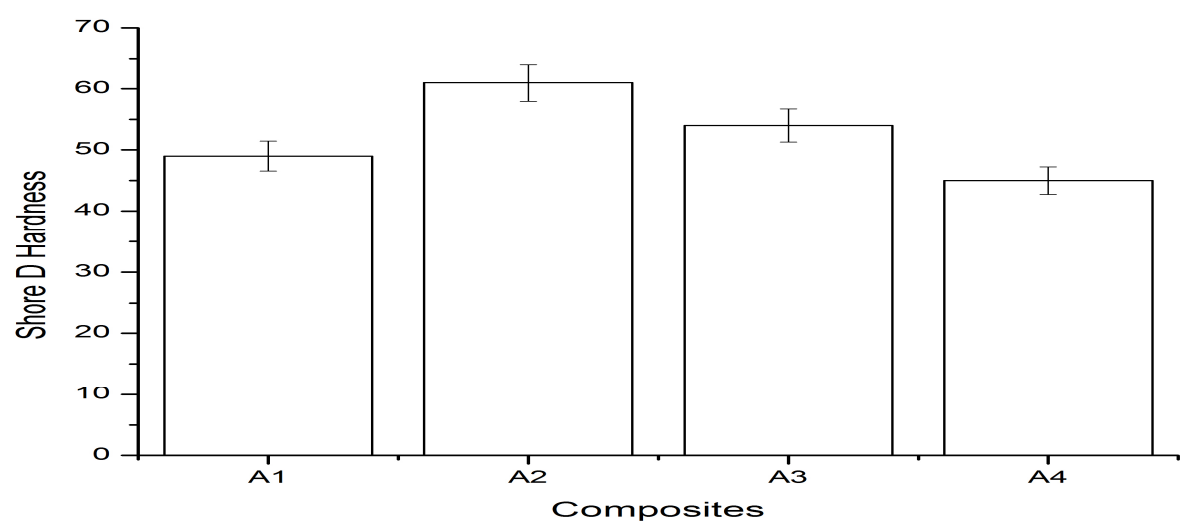

Fig.-7: Shore D hardness of Treated and Untreated Composites in Stated Proportions

Shore D hardness of the treated and untreated fibres are shown in Fig.-7. Shore D hardness of any composite can be defined as the resistance to the indentation. The values of shore $\mathrm{D}$ hardness was maximum when the composites possessed fibres treated with $\mathrm{NaOH}$. The increase in shore $\mathrm{D}$ hardness values is due to the proper bonding between the fibre and matrix. The shore-D hardness values were least for composites when the fibre was treated with $\mathrm{HCl}$ which is due to the improper bonding of the fibres and matrix.

\section{SEM Analysis}

In order to study the fracture interface characteristics of untreated and alkali treated composites, the tensile fracture interface of A4 and A2 composites were chosen and shown in Fig.-8 a, b, c and d respectively. The 
RASĀYAN J. Chem.

Vol. 11 | No. 3 |1255 - 1262 | July - September | 2018

$\mathrm{HCl}$ treated composites as shown in figure 8 (a) showed more fibre pull out and matrix cracks, this is mainly due to the improper wetting of the fibres with the matrix. During the failure, if the fibre is unable to withstand the load, then the load will be transferred to matrix leading to cracks since there is more erosion of the fibre due to acid treatment. Another important consequence of improper bonding of fibre is fibre tear during failure since the surface of the fibres doesn't possess interlocks for the matrix to adhere, this creates the fibre to get torn leading to poor results. Figure- $8 \mathrm{~b}$ shows the cracks propulsion in the matrix and fibre interface; this may further lead to the fibre pull out. In the case of treated fibre composites (A2) Fig.-8c showed good fibre bonding with the matrix. This good adhesion with the matrix is mainly due to the surface treatment which enhances the wettability of the fibre surface with the matrix. Also, it is worth noting that the adhesion level is more without any fibre debonding and crack propulsion in the fibre-matrix interface. In the case of Fig.-8d, the closure view of the surface-treated fibre is shown which possess rough surface which enables interlocks for the matrix bonding. This enhanced bonding helps to increase the mechanical properties.
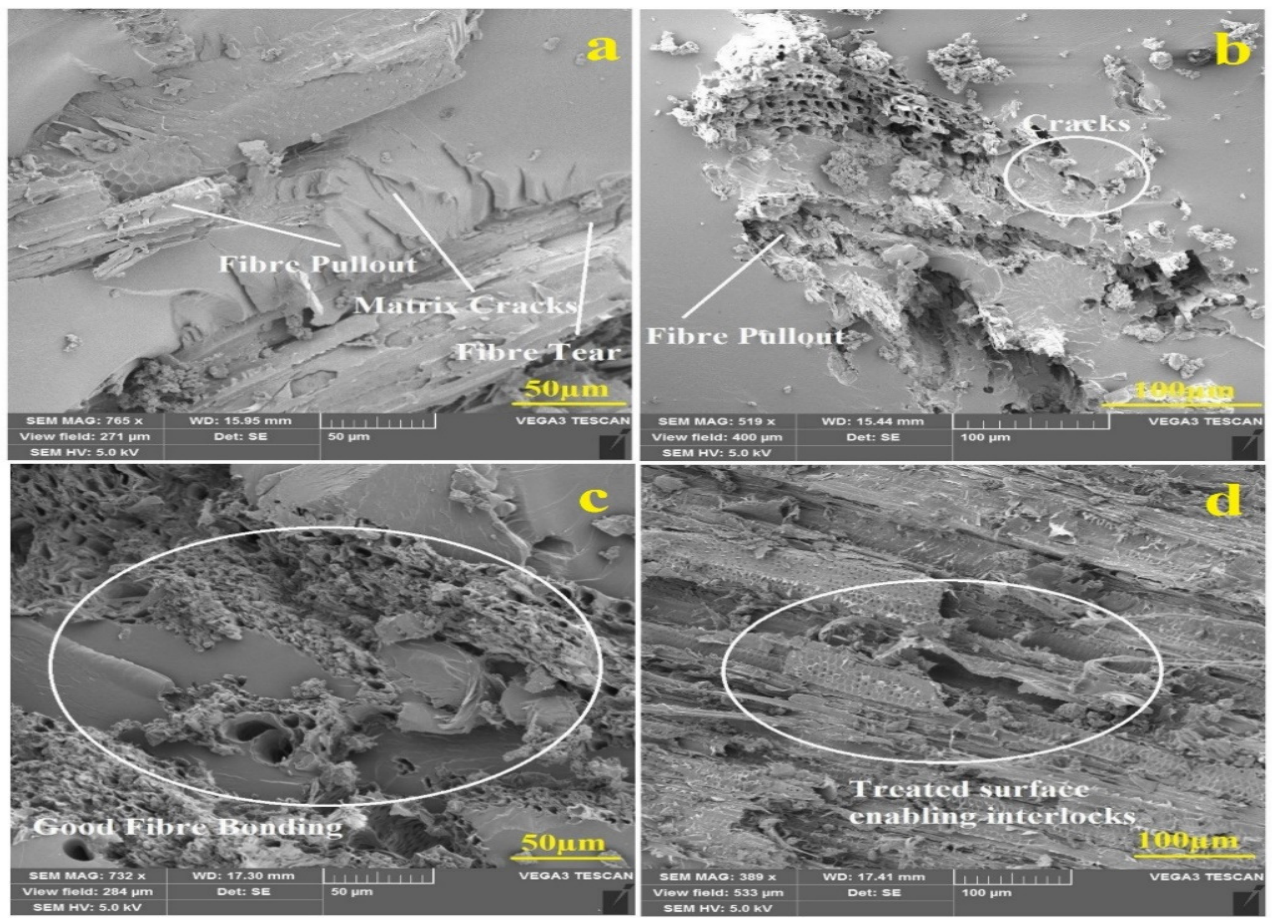

Fig.-8: SEM Images of (a and b) A4 ( $\mathrm{HCl}$ treated Composite), (c and d) A2 (Alkali Treated Composite)

\section{CONCLUSION}

The areca sheath fibre and flax fibres were treated with $\mathrm{HCl}, \mathrm{NaOH}$ and Benzoyl treatment and it was compared with the untreated one. The processing of the composites was carried out using hand layup techniques. The processed composites were characterized for mechanical and morphological characteristics. The following conclusions can be drawn:

1. From the results of mechanical tests, it was found that $\mathrm{NaOH}$ treated fibre composite was as superior one when compared to the other treated and untreated fibres. The improvement of the properties is due to the proper adhesion of fibres with the matrix.

2. $\mathrm{HCl}$ treated fibre based composites showed the least mechanical properties due to the erosion of the fibre surface caused by the acidic attack.

3. FTIR analysis showed the bond stretching caused by the various treatment on the chemical constituents of the fibres.

4. SEM studies of the fractured surfaces show a rough surface on the fibre which assists interlocks for the matrix bonding. This enhanced bonding helps to increase the mechanical properties. Thus there was a correlation between the experimental results and SEM studies. 
5. Thus $\mathrm{NaOH}$ treatment can be optimally used for enhancing the fibre-matrix bonding characteristics to enhance the application suitability of the composites.

\section{REFERENCES}

1. J. Rout, M. Misra, S. S. Tripathy, S. K. Nayak and A. K. Mohanty, Composites Science and Technology, 61(9), 1303 (2001), DOI: 10.1016/S0266-3538(01)00021-5

2. A. K. Bledzki and J. Gassan, Progress in polymer science, 24(2), 221 (1999), DOI: 10.1016/S00796700(98)00018-5

3. M. R. Sanjay, G. R. Arpitha, L. L. Naik, K. Gopalakrishna and B. Yogesha, Natural Resources, 7(03), 108 (2016), DOI: 10.4236/nr.2016.73011

4. M. M. Kabir, H. Wang, K. T. Lau and F. Cardona, Composites Part B: Engineering, 43(7), 2883 (2012), DOI:10.1016/j.compositesb.2012.04.053

5. J. Madhukiran, T. Venkateswara Rao, S. Madhusudan, R. Umamaheswara Rao, International Journal of Engineering Research And Development, 13(9),43(2017).

6. N. Venkateshwaran, A. Elayaperumal, and G. K. Sathiya, Composites Part B: Engineering, 43(2), 793(2012), DOI: 10.1016/j.compositesb.2011.08.023

7. S. L. Gao and E. Mäder, Composites Science and Technology, 66(7-8), 952 (2006), DOI: 10.1016/j.compscitech.2005.08.009

8. M. J. John and R. D. Anandjiwala, Polymer composites, 29(2), 187 (2008), DOI: 10.1002/pc.20461

9. K. Stana-Kleinschek, V. Ribitsch, T. Kreže, M. Sfiligoj-Smole and Z. Peršin, Lenzinger Berichte, 82(1), 83 (2003).

10. A. Benyahia, A. Merrouche, M. Rokbi, M., and Z. Kouadri, Composites, 2, (2013).

11. M. Jacob, S. Thomas, and K. T. Varughese, Composites Science and Technology, 64(7-8), 955 (2004), DOI: 10.1016/S0266-3538(03)00261-6

12. M. M. Kabir, H. Wang, K.T. Lau and F. Cardona, Composites Part B: Engineering, 43(7), 2883(2012), DOI: 10.1016/j.compositesb.2012.04.053

13. K. Joseph, S. Thomas, and C. Pavithran, Polymer, 37(23), 5139 (1996), DOI: 10.1016/00323861(96)00144-9

14. M. R. Sanjay and B. Yogesha, Journal of Industrial Textiles, 47(7), 1830 (2018), DOI: $10.1177 / 1528083717710713$

15. M. Chandrasekar, M. R. Ishak, S. M. Sapuan, Z. Leman and M. Jawaid, Plastics, Rubber and Composites, 46(3), 119 (2017), DOI: 10.1080/14658011.2017.1298550

16. M. Maache, A. Bezazi, S. Amroune, F. Scarpa and A. Dufresne, Carbohydrate Polymers, 171, 163 (2017), DOI: 10.1016/j.carbpol.2017.04.096

17. D. Liu, G. Han, J. Huang and Y. Zhang, Carbohydrate polymers, 75(1), 39 (2009), DOI: 10.1016/j.carbpol.2008.06.003

18. C. E. Maepa, J. Jayaramudu, J. O. Okonkwo, S. S. Ray, E. R. Sadiku and J. Ramontja, International Journal of Polymer Analysis and Characterization, 20(2), 99(2015), DOI: 10.1080/1023666X.2014.961118

19. V. Vilay, M. Mariatti, R. M. Taib and M. Todo, Composites Science and Technology, 68(3-4), 631 (2008), DOI: 10.1016/j.compscitech.2007.10.005

20. A.Alawar, A.M. Hamed, and K.Al-Kaabi, Composites Part B: Engineering, 40(7), 601(2009), DOI: 10.1016/j.compositesb.2009.04.018

21. L. Y. Mwaikambo and M. P. Ansell, Die angewandte makromolekulare Chemie, 272(1), 108 (1999), DOI: 10.1002/(SICI)1522-9505(19991201)272:1<108::AID-APMC108>3.0.CO;2-9

[RJC-3096/2018] 